
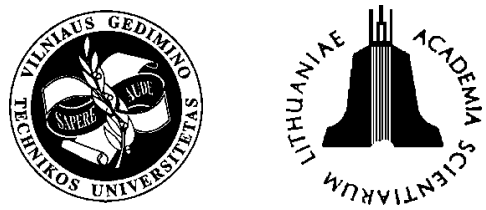

ISSN 1392-3730

JOURNAL OF CIVIL ENGINEERING AND MANAGEMENT

http:/www.vtu.lt/english/editions

2004, Vol X, No 2, 131-141

\title{
ASSESSING THE SAFETY OF EXISTING STRUCTURES: RELIABILITY BASED ASSESSMENT FRAMEWORK, EXAMPLES AND APPLICATION
}

\author{
Luc Schueremans ${ }^{1}$, Dionys Van Gemert ${ }^{2}$ \\ Katholieke Universiteit Leuven, Kasteelpark Arenberg 40, B-3001 Heverlee, Belgium. \\ E-mail:1 luc.schueremans@bwk.kuleuven.ac.be; ${ }^{2}$ dionys.vangemert@bwk.kuleuven.ac.be
}

Received 1 Dec 2003; accepted 12 March 2004

\begin{abstract}
Safety, reliability and risk are key issues in the preservation of our built, cultural heritage. Several structural collapses make us aware of the vulnerability of our technical and natural environment and demand an adequate engineering response. In the analysis phase, an objective way to assess the safety of the structure is essential. The present raises the need for a reliability based assessment framework for existing masonry structures. Although this field of research is relatively young, different techniques have been proposed and optimised. These permit to calculate the global probability of failure of complex structures, relying on deterministic techniques able to calculate the stability state for a prescribed set of parameters. This paper illustrates how these techniques can be a valid tool to evaluate the bearing capacity of existing structures. Focus is on reliability methods based on simulation procedures (Monte Carlo, Directional Sampling), combined with an adaptive meta-model (Response Surface, Splines, Neural Networks). Several benchmark examples demonstrate the applicability of the methodology. The mutual efficiency of the different reliability algorithms is discussed. The application focuses on the assessment of an existing masonry structure. The overall stability of a Romanesque city wall of Leuven (B) is studied in detail. The analysis treats the present safety of the city wall, regarding the uncertainties in load, geometry and resistance. Because of the low degree of safety of several parts of the wall, consolidation measures and strengthening techniques are proposed.
\end{abstract}

Keywords: masonry, safety assessment, failure probability, reliability, Monte Carlo, Splines, Neural Networks.

\section{Introduction}

With approximately 10000 listed and protected monuments, the Belgian Building Heritage is exceptionally rich. The preservation of this unique patrimony requires fundamental effort. The Koning Boudewijn Stichting [1] estimated the total cost necessary to maintain or improve the building heritage to such an extent that it would only require regular maintenance for a reference period of 50 years, to be 2,25 billion EURO. The architectural preservation process is generally based on a sequence of anamnesis and analysis, diagnosis, therapy, control and prognosis [2-4]. In the anamnesis and analysis phase, an objective way to assess the safety of the structure is essential. The present raises the need for a reliability based assessment framework for existing masonry structures [5]. It is in the detailed analysis phase, that a reliability based assessment fits into the framework. It is meant as an objective manner to assess the safety of the existing building, taking into account all kinds of uncertainties inherent to the structures' state. In that it is an objective tool in the decision process. The objective in the prognosis phase is similar. It is meant as a tool to compare possible restoration options, to iden- tify critical parameters and to derive an optimal solution, again accounting for all kinds of (future) uncertainties, such as future loading.

Nowadays, powerful methods are available for the calculation of structural safety values. These permit to calculate the global probability of failure of complex structures, relying on deterministic techniques able to determine the stability state for a prescribed set of parameters.

During history there has been a continuous evolution in refining design methods and consequently assessment methods [6]:

- Level 0 . Initially, the so-called level 0 are used. This level covers rules of thumb and the so-called "elastic method".

- Level I. During the last decades of the 20th century, the level I method has been introduced for several building material applications. These methods are based on the partial safety factor principle. This offers a first objective way to incorporate safety principles into the methodology. Design values are based on characteristic values that on their term are derived from the probability distribution function, obtained via experiments. 
- Level II and III. To obtain an objective value of the probability of failure of a structure, Level II and III methods are proposed in the Eurocode 1. Both are probabilistic techniques. Level II uses first and second order reliability methods (FORM/SORM). These compute the probability of failure where the probability density functions of all random variables are approximated by equivalent normal distribution functions. In that the obtained probability of failure is an estimate of the real probability of failure. Level III methods are most accurate. These compute the exact probability of failure of the whole structural system, or structural elements, using the exact probability density function of all random variables.

The tendency towards level III methods is mainly a matter of computational effort, continuous improvement of reliability algorithms, availability of material data and user-friendly software applications. Because of the increasing computational capacity and speed, probabilistic design according to a preset safety level, is within reach. On an international basis, the tendency from design (or "way of thinking") from a partial safety factor method towards a probabilistic method - reliability-based design is clearly visible [7-10].

\section{Reliability analysis}

Reliability concepts become widely spread as a basis for structural evaluation in design and assessment. Simulation based procedures are very attractive to be used because of their inherent simplicity. One of the major disadvantages, however, is the large number of simulations required to obtain sufficiently accurate results. Because of the complexity of large structures, and thus significant computation time to calculate the outcome of the limit state function, the processing time might become unrealistic. To meet this disadvantage, reliability analysis based on simulation methods in combination with an Adaptive Meta-Model are developed. The procedure is such that the number of calls to the original limit state function is minimised, that a sufficient accuracy for the resulting failure probability is obtained and that the methodology remains applicable for a high number of (random) variables [10].

The use of a Response Surface in combination with a simulation method to increase the efficiency is widely spread [9;11-17]. The main idea is that the response consisting of a complex function of input variables is approximated by a simple function of the input variables. If the Response Surface is capable of handling the complex structural behaviour, the reliability analysis can be performed on the Response Surface, instead of using the original problem. The applicability has been demonstrated extensively [10]. Up to now, often a low order polynomial is used for the Response Surface. Ideally, no functional form is preset and a 'universal estimator' is used. Two extensions are proposed as Meta-Model (MM) in- stead of the low order polynomial Response Surface (RS) that is often used:

- Splines (SP). Piecewise continuous polynomials allow more complex structural behaviour to be redefined in small areas. The sequence of these pieces provides a better estimate of the real structural behaviour for a large domain of input variables;

- Neural Networks (NN). Ideally, no functional form should be predefined and some kind of 'universal estimator' is used. Neural Networks reply to this criteria and therefore offer an interesting perspective [18-21]. The weighting functions that are the basis of the network, are very flexible and adopt to virtually any kind of functional behaviour. Therefore, there are no limits as to shape, dimension, singularity or type of function.

Both have similar properties compared to a loworder polynomial:

- The Meta-Model replaces the (implicit and often complex) limit state function (LSF). Thus the number of direct calls to the limit state function is reduced;

- The evaluation of the Meta-Model does only require simple mathematics to calculate the outcome. This only demands little CPU time.

Using Splines or Neural Network, however, has additional advantages:

- Because of their flexibility, Splines and Neural Networks are a more universal estimator. These are able to capture more complex limit state functions that might not be represented well by means of a 2nd order polynomial;

- Depending on the available data gathered during the simulation process, the complexity of the MetaModel is adapted. Initially, simple models are used. When more data become available, these models are gradually refined.

\subsection{Global reliability framework}

Using a Meta-Model and performing the reliability analysis on the Meta-Model instead of the real limit state function, might be a shift of effort. The number of limit state function evaluations (LSFE) required to build an accurate Meta-Model might be equally large. Often a design of experiments is based on Latin Hyper-cube or a Central Composite Design [15]. The number of experiments increases exponentially with the number of random variables $(n): n_{L S F E} \sim 2^{n}$. Therefore, Waarts developed an adaptive scheme that minimises the number of direct calls to the LSF. It consists of 3 main steps. A detailed description can be found elsewhere [10, 22-24]:

Step 1. The value of each random variable is increased individually until the root $(\lambda)$ of the limit state is found in the standard normal space, $u$-space. This can be seen as an Axis Directional Integration procedure. 
First, a linear estimate is calculated, based on the outcome (LSFE) in the origin of the $u$-space (standard normal space) $(0,0,0, \ldots, 0)$ and the point $\left(0,0, \ldots, \pm \beta_{0}, \ldots, 0\right)$. When known, the start value $\beta_{0}$ is set equal to the expected reliability index b. Experience shows that $\beta_{0}=3$ performs good as well. Further approximations are based on a piecewise continuous polynomial fit of 2 nd order through the outcome (LSFE) of the different iteration points. Mostly after 3 to 4 iterations (LSFE) the root is found, assumed there is a root in the specified direction.

Step 2. An initial Meta-Model (RS, SP, NN) is fit through the data.

Step 3. This step is an iterative procedure. The Meta-Model is adapted (Adaptive method (A)) and the failure probability or reliability index are updated until the required accuracy is reached. Therefore, coarse Directional Sampling (DS) or Monte Carlo Sampling with Variance Increase (MC+VI) is performed on the MetaModel. If the sample or its outcome is judged to be outside the important region, then the outcome based on the Meta-Model is used. If, on the other hand, the sample or its outcome is in the important region, a new LSFE is performed. Afterwards, the Meta-Model is updated as soon as new data are available.

\subsection{Directional Sampling - distinction between important and unimportant region}

In the iterative procedure, Step 3, Crude Directional Sampling is performed on the Meta-Model. It is proved that the expected value $\left(\hat{p}_{f}\right)$ of all contributions is an unbiased estimate of the global failure probability (pf) [8]:

$$
p_{f}=E\left(\hat{p}_{f}\right)=\frac{1}{N} \sum_{i=1}^{N} \hat{p}_{i},
$$

where

$$
\hat{p}_{i}=\chi_{n}^{2}\left(\lambda_{M M, i} \text { or }: \lambda_{L S F E, i}\right)
$$

For each sample, a first estimate of the distance $\lambda_{M M, i}$ to the origin in the standard normal space, $u$ space, is made based on the Meta-Model, that is built in the physical space $-x$-space. An additional distance $\lambda_{\text {add }}$ is used to make distinction between important and less important directions: $\lambda_{M M, i}<\lambda_{\text {min }}+\lambda_{a d d}$, in which $\lambda_{\text {min }}$ is the minimum distance found so far Fig 1 . The additional distance (ladd) is based on the difference between the root of the real LSFE and the root of the Meta-Model in the sample direction. The $99 \%$ confidence interval is taken as measure for $\lambda_{a d d}$ :

$$
\begin{gathered}
\lambda_{a d d}=\max \left\{a b s\left(\mu\left(\varepsilon_{r t}\right) \pm t_{0.01, n_{r t}-1} \times \sigma\left(\varepsilon_{r t}\right)\right)\right\}, \\
\varepsilon_{r t, i}=u_{r t, L S F E, i}-u_{r t, M M, i} .
\end{gathered}
$$

When a good agreement is found between the roots of the real LSF and the Meta-Model, a low value of the additional distance $\left(\lambda_{a d d}\right)$ is obtained; in other cases the distance will be larger. The higher the distance, the more LSFE are performed. In case the obtained root
(1MM,i) has a relatively high contribution $-\lambda_{M M, i}<$ $\lambda_{\text {min }}+\lambda_{\text {add }}-$ to the estimated global failure probability $\left(p_{f}\right)$, the root of the real response is used instead of the Response Surface: $\lambda_{L S F E, i}$. This requires several extra limit state function evaluations. The value obtained by the Meta-Model is used as starting point. Afterwards, the Meta-Model and the additional distance $\left(\lambda_{\text {add }}\right)$ are updated with these new data. In case the contribution is less important $-\lambda_{M M, i}>\lambda_{\text {min }}+\lambda_{\text {add }}-$ the contribution based on the root of the Meta-Model $\left(\lambda_{M M, i}\right)$ is used, avoiding time consuming limit state function evaluations (LSFE). The latter is the main gain of the methodology used.

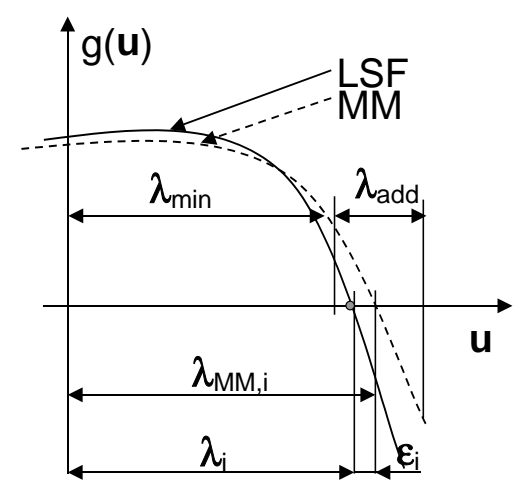

Fig 1. Additional distance in the input space $\left(\lambda_{a d d}\right)$

\subsection{Monte Carlo Variance Increase - distinction between important and unimportant region}

Step 3 in the analysis can be performed using Monte Carlo Sampling with variance increase on the MetaModel as well $[10,22]$. Again, the expected value $\hat{p}_{f}$ of all contributions is an unbiased estimate of the global failure probability $\left(p_{f}\right)[8,25]$ :

$$
p_{f}=E\left(\hat{p}_{f}\right)=\frac{1}{N} \sum_{i=1}^{N}\left\{I\left[g\left(\mathbf{v}_{i}\right)<0\right] \frac{f_{\mathbf{X}}\left(\hat{\mathbf{v}}_{i}\right)}{h_{\mathbf{v}}\left(\hat{\mathbf{v}}_{i}\right)}\right\} .
$$

The variances of the sampling function $h_{v}(v)$ are taken equal to [10]:

$$
\sigma_{h}^{2}=\left(\beta n^{-0.4}\right)^{2}
$$

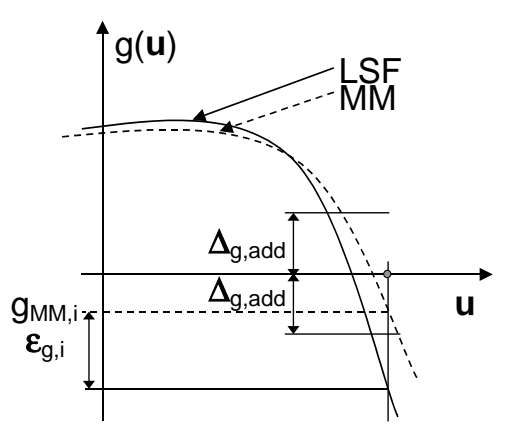

Fig 2. Additional distance in the outcome space $\left(\Delta_{g, a d d}\right)$ 
The initial value for $\beta$ is taken from the Axis Directional Integration, Step 1 in the analysis.

The efficiency is believed to be comparable. To distinguish the important from the non-important region, the magnitude of the outcome values is checked. When the values are small: $g_{M M, i}<\Delta_{g, a d d}$, the sample is believed to be near the limit between safe and unsafe (Fig 2). In that case the outcome is recalculated based on the LSF. This only requires a single LSFE. The data are used to update the Meta-Model, the sampling function (variance) and the additional distance in the outcome space $\left(\Delta_{g, a d d}\right)$. Again, the additional distance in the outcome space is related to the error between the Meta-Model and the LSFE. A $99 \%$ confidence interval is preset:

$$
\begin{gathered}
\Delta_{g, a d d}=\max \left\{a b s\left(\mu\left(\varepsilon_{g}\right) \pm t_{0.01, n_{L S F E}-1} \times \sigma\left(\varepsilon_{g}\right)\right)\right\} \\
\varepsilon_{g, i}=g_{L S F E, i}-g_{M M, i} .
\end{gathered}
$$

\section{The applied Meta-Model}

The algorithms are implemented in Matlab [26]. For the implementation of Splines and Neural Networks, use is made of the Splines and Neural Networks Toolboxes available in Matlab. Because of its open programme structure, these could easily be adopted for this purpose.

\subsection{Splines}

The piecewise continuous polynomials are based on the thin plate smoothing Spline concept, that is able to deal with multivariate input and a single output - outcome of the LSF [27] Fig 3.

Because of its simple form, evaluation afterwards is straightforward. The limit state function can be written as:

$$
g_{M M}(\mathbf{x})=\sum_{j=1}^{N} \mathbf{a}_{j} \psi\left(\mathbf{x}-\mathbf{x}_{\mathbf{c}_{j}}\right)
$$

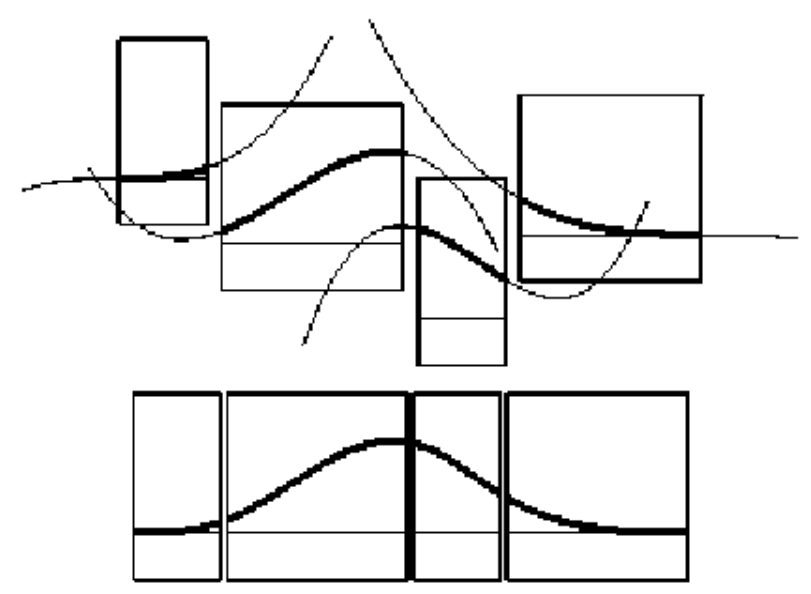

Fig 3. Thin plate smoothing Splines where $g_{M M}(\boldsymbol{x})$ is the Meta-Model of the limit state function $g(\boldsymbol{x})$ in which $\boldsymbol{x}$ is a column vector with size $1 \times n, n$ the number of random variables defining the problem at hand; $\boldsymbol{a}_{j}$ : the smoothing Spline coefficients $(1 \times n) ; \boldsymbol{x}_{c j}$ : the coordinates at which the LSFE is available $(1 \times n)$; and $\psi(\boldsymbol{x})$ : the thin-plate Spline basis function, that equals:

$$
\psi(\mathbf{x})=\|x\|^{2} \log \left(\|x\|^{2}\right)
$$

This thin-plate smoothing Spline $\operatorname{gMM}(\mathrm{x})$ is the unique minimiser of a weighted sum error measure. A detailed description can be found elsewhere [23-24, 27].

\subsection{Neural Networks}

The use of Neural Networks as Meta-Model for the limit state function remains marginal [28-30]. A single neuron $k$ is not capable of describing an arbitrarily relationship in an accurate way (Fig 4). The output of neuron $k$ as a function of the input signals $x_{i}$ is described as:

$$
y_{k}=\varphi\left(\sum_{i=1}^{n} w_{k, i} x_{i}+\theta_{k}\right),
$$

where $x_{i}(i=1 . . n)$ are the input signals; $w_{k, i}:$ weights; $\theta_{k}$ : bias term; and $\varphi$ : activating function (often sigmoidal).

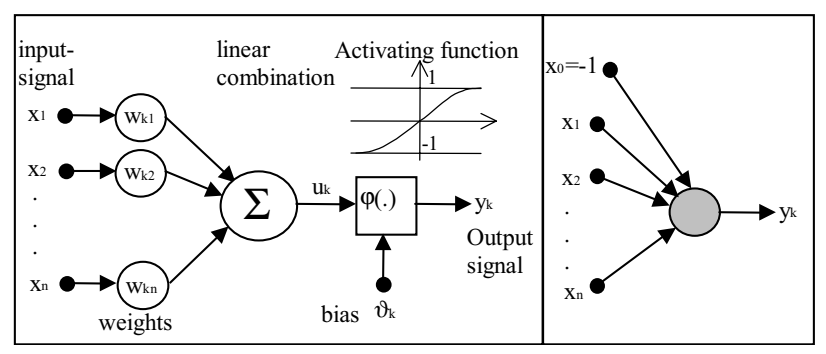

Fig 4. Model of a single neuron

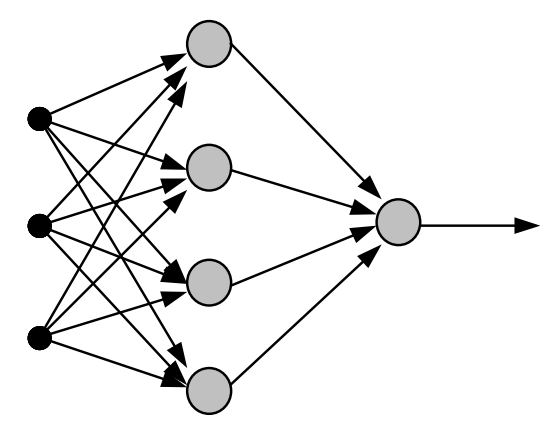

$\begin{array}{lll}\text { Input-signals } & \text { Level with } & \text { Level with } \\ \text { with source } & \text { hidden } & \text { output } \\ \text { nodes } & \text { neurons } & \text { neurons }\end{array}$

Fig 5. Multiplayer network architecture - multilayered feed-forward network $\left(n-n_{n}-1: 3-4-1\right)$

Multilayer networks, however, are quite powerful (Fig 5). For instance, a network of two layers, where the first layer is sigmoid and the second layer is linear, can be trained to approximate any function (with a finite number of discontinuities) arbitrarily well. This network 
architecture seems to be a valid alternative, not often looked at.

Different learning rules exist as a procedure for modifying the weights $\left(w_{k, i}\right)$ and biases $\left(\mathrm{q}_{k}\right)$ of a network [31]. All of these algorithms use the gradient of the performance function - direction of the steepest decent - to determine how to adjust the weights to minimise performance. The performance function for this type of feedforward networks is the mean square error - the average error between the network outputs and the target outputs. The target outputs are those, obtained from experiments. The step-size in the direction of the steepest decent is optimised and may vary during the learning process [32]. To further increase the convergence speed, quasi Newton learning rules are applied, such as the Levenberg-Marquardt learning rule. The Hessian-matrix of second-order derivatives of the performance function is calculated numerically based on the gradient. Again optimal step-sizes are looked for [33].

\section{Benchmark examples}

The methodology has been validated using 15 benchmark examples. These examples cover a wide variety of possible limit state functions of varying complexity. The examples were developed to compare different reliability methods with respect to the following preset criteria $[10,22]$ : multiple critical points, noisy boundaries, unions and intersections (system behaviour), space dimension ( $n$ : number of random variables), probability level, strong curvatures in the LSF and no roots in the axis direction. Benchmark example 12 and 15 are highlighted. The individual results of the other benchmark examples can be found elsewhere [34].

\subsection{Benchmark example 12 - series system with 4 branches}

The limit state function has 4 branches (Eq 12). Both variables are standard normal distributed random variables. The results of the reliability analysis are summarised in Table 1.

$$
g=\min \left\{\begin{array}{l}
3,0+0.1\left(u_{1}-u_{2}\right)^{2}-\left(u_{1}+u_{2}\right) / \sqrt{2} \\
3,0+0.1\left(u_{1}-u_{2}\right)^{2}+\left(u_{1}+u_{2}\right) / \sqrt{2} \\
\left(u_{1}-u_{2}\right)+3,5 \sqrt{2} \\
\left(u_{2}-u_{1}\right)+3,5 \sqrt{2}
\end{array}\right.
$$

\subsection{Benchmark example 15 - cantilever beam}

The structure under consideration is a cantilever beam with rectangular cross-section. The beam is subjected to a uniformly distributed load. The resulting limit state function reads [35]:

$$
g=18,461-7,477 \times 10^{10} \frac{x_{1}}{x_{2}^{3}} .
$$

Table 1. Benchmark example 12 - reliability analysis

\begin{tabular}{l|c|c|c|c}
\hline Simulation method & \multicolumn{4}{|c}{ Directional Sampling } \\
\hline Adaptive Meta-Model & $/$ & $\mathrm{RS}$ & $\mathrm{SP}$ & $\mathrm{NN}$ \\
\hline$\beta(\equiv 2,85)$ & 2,79 & 3,03 & 3,00 & 3,05 \\
$\mathrm{p}_{\mathrm{f}}$ & 0,0026 & 0,001 & 0,001 & 0,001 \\
$\mathrm{~N}$ & 2750 & 500 & 375 & 800 \\
$\mathrm{n}_{\text {LSFE }}$ & 9192 & 830 & 107 & 67 \\
$\lambda_{\text {add }} / / \Delta_{\text {g;add }}$ & $/$ & 1,77 & 0,20 & 0,025 \\
\hline Simulation method & \multicolumn{4}{|c}{ Monte Carlo with Variance } \\
\hline AMMl & $/$ & RS & SP & $\mathrm{NN}$ \\
\hline$\beta(\equiv 2,85)$ & 2,84 & 2,84 & 2,81 & 2,76 \\
$\mathrm{p}_{\mathrm{f}}$ & 0,0022 & 0,002 & 0,002 & 0,0029 \\
$\mathrm{~N}$ & 4750 & 5402 & 3753 & 5651 \\
$\mathrm{n}_{\text {LSFE }}$ & 4750 & 3877 & 724 & 125 \\
$\lambda_{\text {add }} / / \Delta_{\text {g;add }}$ & $/$ & 1,83 & 0,05 & 0,04 \\
\hline
\end{tabular}

Legend: preset accuracy for convergence: $\sigma(\beta)=0,15 . N$ is the number of samples in the simulation process; $n_{L S F E}$ : number of limit state function evaluations; DS: Directional Sampling; MC+VI: Monte Carlo with Variance Increase; RS: pure quadratic polynomial Response Surface; SP: Splines; NN: feed-forward Neural Network $\left(n-n_{n}-1\right.$ : with $n_{n}$ the number of neurons in the hidden layer $\left.-n_{n}=2 n+n_{L S F E} / 4\right)$; learning function: scaled conjugate gradient method

The random variables are summarised in Table 2 . It can be seen that this functional form will not be estimated easily with a low order polynomial. The results of the reliability analysis are presented in Table 3 .

Table 2. Benchmark example 15 - random variables

\begin{tabular}{c|c|c|c}
\hline $\begin{array}{c}\text { Random } \\
\text { variable }\end{array}$ & $\begin{array}{c}\text { Probability density } \\
\text { function }\end{array}$ & Mean value & $\begin{array}{c}\text { Standard } \\
\text { deviation }\end{array}$ \\
\hline $\mathrm{x}_{1}$ & Normal & 0,001 & 0,00002 \\
$\mathrm{x}_{2}$ & Normal & 250,0 & 37,5 \\
\hline
\end{tabular}

Table 3. Benchmark example 15 - reliability analysis

\begin{tabular}{l|c|c|c|c}
\hline Simulation method & \multicolumn{4}{|c}{ Directional Sampling } \\
\hline $\mathrm{AMM}$ & $/$ & $\mathrm{RS}$ & $\mathrm{SP}$ & $\mathrm{NN}$ \\
\hline$\beta(\equiv 2,35)$ & 2,38 & 2,42 & 2,40 & 2,50 \\
$\mathrm{p}_{\mathrm{f}}$ & 0,0085 & 0,0078 & 0,008 & 0,0062 \\
$\mathrm{~N}$ & 288 & 70 & 300 & 69 \\
$\mathrm{n}_{\text {LSFE }}$ & 674 & 135 & 315 & 56 \\
$\lambda_{\text {add }}^{1 / \Delta_{\text {g:add }}}$ & $/$ & 3,27 & 1,36 & 0,34 \\
\hline Simulation method & Monte Carlo with Variance Increase \\
\hline AMM & $/$ & $\mathrm{RS}$ & $\mathrm{SP}$ & $\mathrm{NN}$ \\
\hline$\beta(\equiv 2,35)$ & 2,35 & 2,29 & 2,41 & 2,34 \\
$\mathrm{p}_{\mathrm{f}}$ & 0,0094 & 0,011 & 0,008 & 0,0096 \\
$\mathrm{~N}$ & 10749 & 760 & 1050 & 2120 \\
$\mathrm{n}_{\text {LSFE }}$ & 10749 & 158 & 247 & 39 \\
$\lambda_{\text {add }}^{1 / \Delta_{\text {g;add }}}$ & $/$ & 6,63 & 9,43 & 0,81 \\
\hline
\end{tabular}

Legend: see Table 1 


\subsection{Global efficiency - discussion of results}

It has already been demonstrated that, given a preset accuracy, the number of calls to the real LSF remains proportional to the number of random variables [10]. The proportionality is mainly function of the preset accuracy on the obtained reliability index or failure probability and the complexity of the original LSF. The proportionality $(k)$ is mainly function of the preset accuracy on the obtained reliability index or failure probability and the complexity of the original LSF. The latter is demonstrated by the large spread on the proportionality $(k)$. The values listed in Table 2 are derived from the 15 benchmark examples treated.

Table 4. Global efficiency

\begin{tabular}{l|c|c|c|c}
\hline$n_{L S F E}=k n$ & \multicolumn{5}{c}{ Directional Sampling } \\
\hline$(\mathrm{A})$ Meta-Model & $/$ & RS & SP & NN \\
\hline$\mu(k)$ & 1834 & 80 & 50 & 47 \\
$\sigma(k)$ & 2288 & 121 & 48 & 36 \\
\hline$n_{L S F E}=k n$ & \multicolumn{5}{|c|}{ Monte Carlo with Variance Increase } \\
\hline$(\mathrm{A})$ Meta-Model & $/$ & RS & SP & NN \\
\hline$\mu(k)$ & 2327 & 452 & 83 & 35 \\
$\sigma(k)$ & 2299 & 983 & 93 & 43 \\
\hline
\end{tabular}

From these benchmark examples, the efficiency of applying a Meta-Model is evidenced.

The different techniques all result in a good estimate of the system reliability. System behaviour is accounted for intrinsically. The overall efficiency of DS and $\mathrm{MC}+\mathrm{VI}$ plus an adaptive Meta-Model is comparable and depends on the problem at hand. If several directions in the standard normal space ( $u$-space) have a comparable contribution to the global failure probability, DS will be more efficient. This is the case in benchmark example 12, Table 1.

Advantage of the DS procedure is that it finds the roots of the LSF, where MC+VI only returns the outcome of the LSF for each sample given. The roots of the LSF contain interesting information with respect to the failure modes of the structural system. On the other hand, MC+VI does not require any complex root-finding algorithm. Therefore, the procedure remains very simple and straightforward.

The overall efficiency of any type of Adaptive MetaModel is clear from the results listed in Tables 1, 2 and 3 . Whenever the low order polynomial Response Surface is not capable of estimating the real LSF behaviour accurately, the use of Splines (SP) or Neural Networks $(\mathrm{NN})$ is beneficial. Splines and even more Neural Networks are far better in estimating more complex system behaviour. This results in a lower number of calls to the real limit state function. This is evidenced from a mutual comparison of the values for $\lambda_{\text {add }}$ (DS) or $\Delta_{\text {g,add }}$ $(\mathrm{MC}+\mathrm{VI})$, respectively. The smaller these values, the smaller the error in between the Meta-Model and the real limit state function.

A feed forward Neural Network with a $\left(n-n_{n}-1\right)$ network architecture is capable of matching any functional form with limited restrictions. This general statement is, however, function of the number of neurons in the hidden layer: $n_{n}$. Only indicative rules are available. On top of that, finding the weights of the neurons is a global optimization problem. Depending on the size of the problem $\left(n-n_{n}\right)$, this might take significant computational capacity. In large problems with a significant number of random variables $(n)$, it will be a trade of between the CPU in evaluating the real LSF and estimating a NN. With large numbers of random variables, Splines seem to be computationally more efficient. In case the limit state function remains relatively smooth and does not contain discontinuities, the use of Splines is preferable.

The working space in which the Meta-Model is fit, differs from author to author. Up to now, no arguments in favour of one or another have been presented. In this contribution, the experimental design is executed in the standard normal space ( $u$-space). The fitting of the MetaModel, however, is done in the physical space ( $x$-space), because of its physical meaning. In case of using a low order polynomial Response Surface, this might, however, be of importance. Based on the experience of several examples, some of the low order polynomials fit well in the $u$-space but do not result in good estimates of the LSF in the $x$-space or vice versa. This depends on the problem at hand. Furthermore, if a low order polynomial is not capable of capturing the global behaviour of the limit state function, it might be capable of fitting the edge between safe and unsafe. Therefore, when Directional Sampling and an adaptive Response Surface are used, often only the roots are used to estimate the Response Surface. The intermediate values are omitted.

When a more uniform estimator of the limit state function is used, such as Splines or Neural Networks, the difference in quality between a Meta-Model fit in the $x$ - or $u$-space is believed to become smaller. Fitting the roots only is no longer required because of lack of power to capture the overall behaviour.

\section{Practical application - Romanesque city wall}

The Romanesque city wall of Leuven (B) dates from 1150. The medieval wall is in a severe state of decay.

The part studied in this paper is a piece of the edifice between the former Biest- and Minneporte (2 gates). This part of the Romanesque city wall near the river Dijle has a total length of about $150 \mathrm{~m}$ and comprises 2 towers.

\subsection{Problem definition}

This example only covers the most critical part of the wall [35] (Fig 6). A global view of the structural layout of the wall is given in Fig 7. The wall consists of 


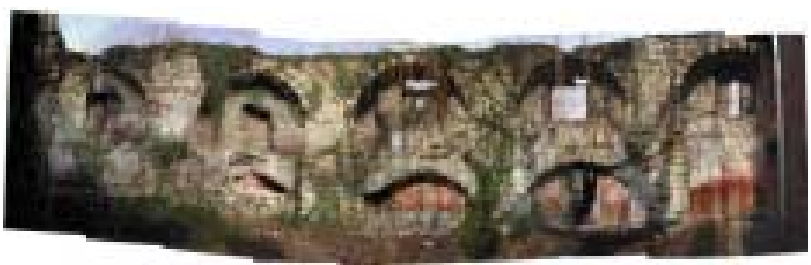

Fig 6. Global overview of the critical part A - city side

an inner or city side (B) and an outer or rural side (A). Round foundation arches of $2 \mathrm{~m}$ high and 3,5 to $4 \mathrm{~m}$ wide carry the outer wall. The inner wall is a continuous arcade of $4 \mathrm{~m}$ wide round arches with their tops $3 \mathrm{~m}$ above the outer arches. A walkway of $0,90 \mathrm{~m}$ width (C) is present on top of the arcades. The outer wall was equipped with shooting holes centred in the arches of the inner part (D) and crowned by a parapet also bearing shooting holes. These are no longer present. On the city side as well as on the rural side, the wall was lined with a sloped embankment (F, E) covering the foundation pillars and arches. This embankment is no longer present at the rural side, and only partly at the city side. For the construction of the wall, a local type of limesandstone (Diegemse Zandsteen) was used. An iron containing sandstone (Diestiaan sandstone) was mainly used for decorative purposes, for example, in the inner arcades.

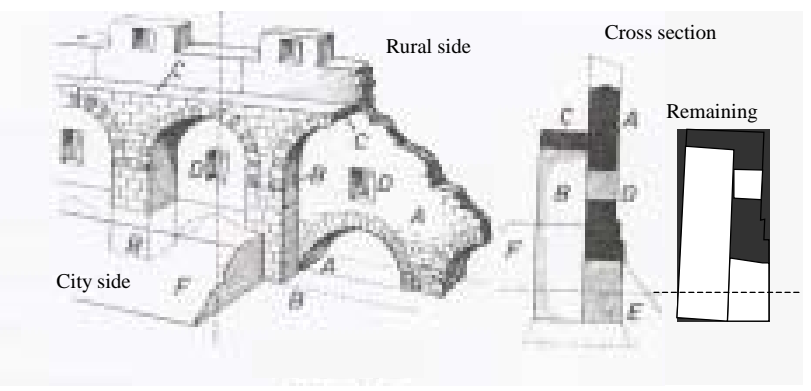

Fig 7. Reconstruction of structural layout of city wall

To assess the structural safety, an extensive survey was conducted in the diagnosis phase. Following items were covered: visual inspection, historic survey, determination of used materials and their physical and chemical properties, foundation survey, soil investigation, photo-grammetric survey and profiles of wall inclination [36].

Determining the target probability of failure is not a technical problem solely. Whether or not an historical building should meet the target probability of failure value $p_{f T}=5,10^{-4}$ according to Eurocode 1 [6], is subject of discussion. Several authors suggest to widen the discussion [22] and propose a differentiation with respect to various performance criteria listed in Table 5. The formula proposed to determine nominal target failure probabilities is a mix of proposals presented by different authors [22]. It is very suitable as it accounts for a so-
Table 5. Factors influencing the nominal target probability of failure (used values in bold)

\begin{tabular}{l|c}
\hline - $t_{L}$ : residual service life [years]: & $\mathbf{1 0 0}$ \\
- $n_{p}:$ number of lives put to danger: & $\mathbf{1 0}$ \\
\hline Economical factor & $\mathrm{C}_{\mathrm{f}}$ \\
\hline - not serious & 10 \\
- serious & $\mathbf{1}$ \\
- very serious & 0,1 \\
\hline Warning factor & $\mathrm{W}$ \\
\hline - Fail -Safe condition & 0,01 \\
- Gradual failure with some warning likely & 0,1 \\
- Gradual failure hidden from view & $\mathbf{0 , 3}$ \\
- Sudden faulure without previuos warning & 1,0 \\
\hline Activity factor & $\mathrm{A}_{\mathrm{c}}$ \\
\hline - Post-disaster activity & 0,3 \\
- Normal activities & $\mathbf{1 , 0}$ \\
$\quad$ Buildings or Bridges & 3,0 \\
\hline High exposure structures (offshore) & 10,0 \\
\hline Social criterion factor (Preservation value) & $\mathrm{S}_{\mathrm{c}}$ \\
\hline - Places of public assembly, dams (historical & $\mathbf{0 , 0 0 5}$ \\
buildings of great importance for mankind, & \\
- listed by UNESCO, eg) & 0,05 \\
- Bomestic buildings, offices, trade buildings, & \\
- Towers, masts, off-shore structures & 0,5 \\
\hline
\end{tabular}

cial criterion that can be reinterpreted to encapsulate the importance of historical buildings or the preservation value. The values used in this analysis are shown in bold, Table 5:

$$
p_{f, T}=\frac{10^{-4} S_{c} t_{L} A_{c} C_{f}}{n_{p} W}=1,667 \times 10^{-5} .
$$

\subsection{Safety assessment}

A single arcade - the repetitive structural element is taken as an individual control unit. To clarify the benefit of using a reliability based assessment, different levels to assess the safety are used:

- Level 0: To obtain a measure for the remaining safety margin, the structure is checked using nominal values for the applied loads and resistances. The resistance-load ratio $(r)$ is used as a measure for the remaining safety margin with respect to a certain ultimate limit state;

- Level I: The analysis is performed according to the partial safety factor method;

- Level III: The analysis is performed using probabilistic evaluation algorithms based on sampling techniques. An accurate value for the system reliability is obtained. The same limit state functions that are used for the Level I analysis, are accounted for. 
The probability density function and the parameters for the different random variables, are listed in Table 6. These cover the different types of uncertainties encountered during the survey: accuracy of the geometry, the uncertainty on the material properties (subsoil and stone masonry), actual loads and future loads.

Following limit states are checked, Table 7, (definition of symbols, Fig 8):

- Rotational-equilibrium. The centre of gravity is determined $\left(y_{g, t o t}\right)$, accounting for the structural geometry and the slant of the wall. As long as the value is positive, the centre of gravity remains within the cross-section, thus the rotation limit state is met. The eccentricity $\left(e_{t o t}\right)$ is checked. Whenever the eccentricity exceeds the mid-third $(d / 6)$, part of the crosssection is in tension. As use is made of a non-tension material model, the force equilibrium is met using compressive stresses only. This leads to an increased stress level [22];

- Compressive stresses are calculated in the masonry $\left(\sigma_{\max }\right)$ as well as in the soil at foundation level $\left(\sigma_{g r, \max , e l}\right.$ and $\left.\sigma_{g r, \max , p l}\right)$. Maximum stresses are found at the foundation tip of the pillars, due to the slant of the wall. For both materials, a non-tension material model is used. For the soil, a linear-elastic $(e l)$ as well as an elastic-plastic $(p l)$ material model is used [22].

Table 6. Romanesque city wall - Random variables

\begin{tabular}{l|c|l|c}
\hline Random variable & PDF & $\begin{array}{l}\text { Mean } \\
\text { value }\end{array}$ & $\begin{array}{c}\text { Std } \\
\text { dev. }\end{array}$ \\
\hline
\end{tabular}

Initial assessment $-\mathrm{n}=23$

\section{Load:}

$\rho_{\mathrm{m}}\left[\mathrm{kN} / \mathrm{m}^{3}\right]$ :density of masonry

Geometry $(\mathrm{n}=17)$

Geometry of wall

Resistance of subsoil:

$\mathrm{c}\left[\mathrm{kN} / \mathrm{m}^{2}\right]$ : cohesion

$\varphi\left[^{\circ}\right]$ : friction coefficientg

$\gamma_{\mathrm{dr}}\left[\mathrm{kN} / \mathrm{m}^{3}\right]$ : dry density

Resistance:

$\mathrm{f}_{\mathrm{m}}$ : stone masonry strength

Uncertainty:

$\varepsilon[\mathrm{m}]:$ model uncertainty

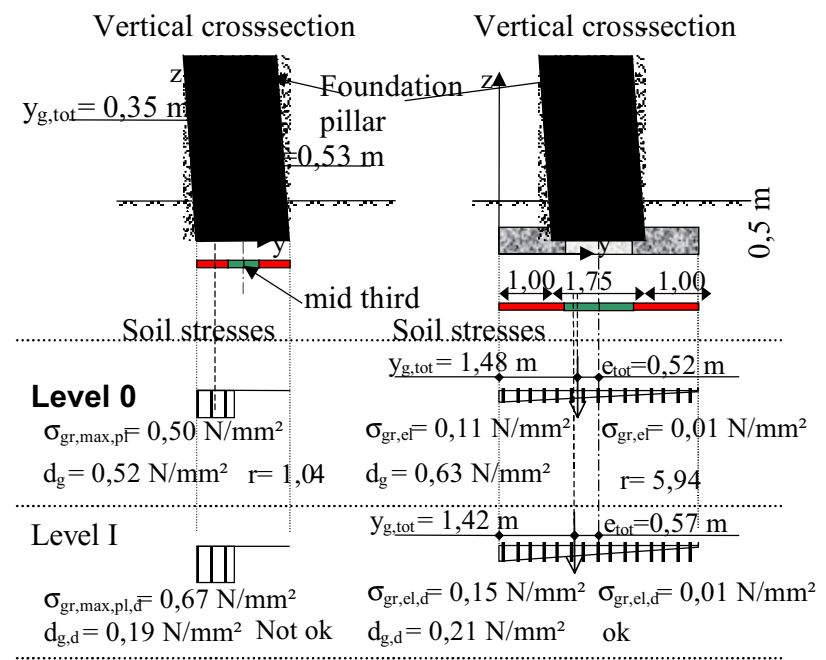

Fig 8. Stress distribution in the subsoil at foundation level - left: original situation; right: with foundation strengthening

The results of the safety assessment of part A of the wall are listed in Table 7. From the Level 0 and Level I analysis, it is clear that the structural stability is in doubt. The remaining safety $(r=1,04)$ is limited; the limit state function of the stresses in the subsoil is violated. The probabilistic method offers an objective way to assess the remaining safety, accounting for the present uncertainties: $p_{f}=0,12$. This value does not meet the preset target value.

Besides the general remarks already stated from the benchmark examples, it is clear from Table 8 that the efficiency of the different Meta-Models is comparable. This can be seen from the additional distances $\lambda_{\text {add }} / / \Delta_{\text {g,add }}$, as well for the DS as for the MC+VI sampling procedures. In case the limit state function can be estimated relatively well by a low order polynomial, the additional benefit in using Splines or Neural Networks is limited.

Table 7. Results of structural reliability

\begin{tabular}{|c|c|c|c|}
\hline $\begin{array}{l}\mathrm{LSF} / / \\
\text { Assessment } \\
\text { level }\end{array}$ & $\begin{array}{l}\text { Rotation } \\
\text { equilibrium } \\
{[\mathrm{m}]}\end{array}$ & $\begin{array}{l}\text { Stresses in the } \\
\text { masonry } \\
{\left[\mathrm{N} / \mathrm{mm}^{2}\right]}\end{array}$ & $\begin{array}{c}\text { Stresses in the } \\
\text { subsoil } \\
{\left[\mathrm{N} / \mathrm{mm}^{2}\right]}\end{array}$ \\
\hline Level 0 & & $\begin{array}{l}\sigma_{\mathrm{m}, \max }=0,74< \\
\mathrm{f}_{\mathrm{c}, \mathrm{m}}=23,2 \\
\mathbf{r}=\mathbf{3 0 , 5}\end{array}$ & $\begin{array}{l}\sigma_{\mathrm{gr}, \max , \mathrm{pl}}=0,50< \\
\mathrm{d}_{\mathrm{g}}=0,52 \\
\mathbf{r}=\mathbf{1 , 0 4}\end{array}$ \\
\hline Level I & $\begin{array}{l}y_{\text {g,tot }}=0,35>0 \\
(\text { OK }) \\
e_{\text {tot }}=0,53> \\
d / 6=0,29 \\
\text { NOT OK }\end{array}$ & $\begin{array}{l}\sigma_{\mathrm{m}, \max , \mathrm{d}}=1,00< \\
\mathrm{f}_{\mathrm{c}, \mathrm{m}, \mathrm{d}}=16,2 \\
\mathrm{OK}\end{array}$ & $\begin{array}{l}\sigma_{\text {gr,max,el,d }}= \\
0,90>d_{g, d}= \\
0,19 \\
\text { NOT OK }\end{array}$ \\
\hline Level III & \multicolumn{3}{|c|}{$\begin{array}{l}\text { System reliability } \beta=\mathbf{1 , 2}<\beta_{\mathrm{T}}=\mathbf{4 , 2} \\
\text { Corresponding failure probability: } \\
\mathbf{p}_{\mathbf{f}}=\mathbf{0 , 1 1}>\mathbf{p}_{\mathbf{f}, \mathbf{T}}=\mathbf{1 , 7} \mathbf{1 0}^{-5}\end{array}$} \\
\hline
\end{tabular}


Table 8. Comparative results of reliability analysis

\begin{tabular}{|c|c|c|c|c|}
\hline \multirow{2}{*}{$\begin{array}{l}\begin{array}{l}\text { Simulation } \\
\text { method }\end{array} \\
\text { Adaptive } \\
\text { Meta-Model }\end{array}$} & \multicolumn{4}{|c|}{ Directional Sampling } \\
\hline & / & $\mathrm{RS}$ & SP & NN \\
\hline$\beta(\equiv 1,217)$ & 1,16 & 1,15 & 1,23 & 1,15 \\
\hline $\mathrm{p}_{\mathrm{f}}$ & 0,12 & 0,13 & 0,11 & 0,13 \\
\hline $\mathrm{N}$ & 4000 & 1658 & 508 & 3408 \\
\hline $\mathrm{n}_{\text {LSFE }}$ & 7253 & 269 & 166 & 196 \\
\hline$\lambda_{\text {add }}^{L S F} / / \Delta_{\text {g;add }}$ & l & 0,60 & 0,23 & 0,33 \\
\hline $\begin{array}{l}\text { Simulation } \\
\text { method }\end{array}$ & \multicolumn{4}{|c|}{ Monte Carlo with Variance Increase } \\
\hline $\begin{array}{l}\text { Adaptive } \\
\text { Meta-Model }\end{array}$ & & $\mathrm{RS}$ & SP & $\mathrm{NN}$ \\
\hline$\beta(\equiv 1,217)$ & 1,27 & 1,23 & 1,29 & 1,18 \\
\hline $\mathrm{p}_{\mathrm{f}}$ & 0,10 & 0,11 & 0,10 & 0,12 \\
\hline $\mathrm{N}$ & 20042 & 700 & 949 & 1545 \\
\hline $\mathrm{n}_{\text {LSFE }}$ & 20042 & 124 & 152 & 215 \\
\hline$\lambda_{\text {add }}^{L S F} / / \Delta_{\text {g;add }}$ & / & 0,17 & 0,14 & 0,11 \\
\hline
\end{tabular}

Legend: preset accuracy for convergence: $\sigma(\beta)=0,15$. $\mathrm{N}$ is the number of samples in the simulation process; $n_{L S F E}:$ number of limit state function evaluations; DS: Directional Sampling; MC+VI: Monte Carlo with Variance Increase; RS: pure quadratic polynomial Response Surface; SP: Splines; NN: feed-forward Neural Network $\left(n-n_{n}-1\right.$ : with $n_{n}$ the number of neurons in the hidden layer $-n_{n}=n+n_{L S F E} / 4$ ); learning function: scaled conjugate gradient method

The following remarks can be made and overlap with the conclusions stated from the benchmark examples:

- Crude Directional Sampling and Monte Carlo with variance increase do require significantly more LSFE compared to the simulation procedures with an adaptive Meta-Model. The use of any Meta-Model is evident;

- The efficiency of the different Meta-Models is comparable. This can be seen from the comparable values for the additional distances $\lambda_{\text {add }} / / \Delta_{\text {g,add }}$, as well for the DS as for the MC+VI sampling procedures.

- In all cases an accurate value for the system failure probability is obtained.

\subsection{Strengthening - reliability-based design}

The lack of safety originates from the limited loadbearing capacity of the soil in combination with the large slant of the wall. This is partly caused by the removal of the original sloped embankments at the rural and city side. At present, the top part of the foundation is above the original ground level. Thus, the depth of the foundation decreased significantly. To increase the safety to an acceptable level, two options are available:

- Widen the foundation at the support. This will reduce the soil stresses (Fig 9);

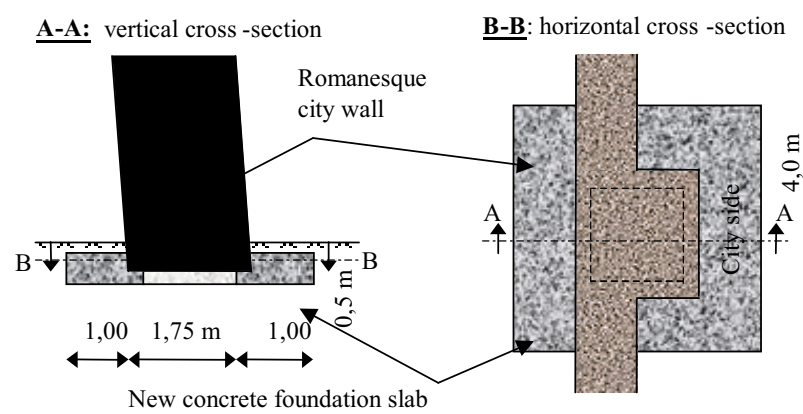

Fig 9. Foundation strengthening - new reinforced concrete foundation slab

- Increase the load-bearing capacity of the soil by restoring the original sloped embankment at rural side.

For this part of the wall, a strengthening of the foundation is proposed. A new concrete foundation slab will be established at the basis of the existing foundation (Fig 9) for a schematic representation. This reduces the soil stresses at the support. The effect of these strengthening measures on the structural safety is recalculated. The results are summarised in Table 9 and visualised in (Fig 8). In all cases, a sufficient safety margin is obtained.

Table 9. Summary of structural safety for part A of the wallstrengthened situation

\begin{tabular}{|c|c|c|c|}
\hline $\begin{array}{l}\text { LSF - } \\
\text { Assessment } \\
\quad \text { level }\end{array}$ & $\begin{array}{l}\text { Rotation } \\
\text { equilibrium } \\
{[\mathrm{m}]}\end{array}$ & $\begin{array}{l}\text { Stresses in } \\
\text { the masonry } \\
{\left[\mathrm{N} / \mathrm{mm}^{2}\right]}\end{array}$ & $\begin{array}{l}\text { Stresses in the } \\
\text { subsoil } \\
{\left[\mathrm{N} / \mathrm{mm}^{2}\right]}\end{array}$ \\
\hline Level 0 & & $\begin{array}{l}\sigma_{\operatorname{m,max}}=0,74 \\
<f_{c, m}=23,2 \\
\mathbf{r}=\mathbf{3 0 , 5}\end{array}$ & $\begin{array}{l}\sigma_{\mathrm{gr}, \max , \mathrm{el}}=0,11< \\
\mathrm{d}_{\mathrm{g}}=0,63 \\
\mathbf{r}=\mathbf{5 , 9 4}\end{array}$ \\
\hline Level I & $\begin{array}{l}y_{\mathrm{g}, \text { tot }}=1,77>0 \\
\mathrm{e}_{\text {tot }}=0,35< \\
\mathrm{d} / 6\end{array}$ & $\begin{array}{l}\sigma_{\mathrm{m}, \max , \mathrm{d}}= \\
1,00<\mathrm{f}_{\mathrm{c}, \mathrm{m}, \mathrm{d}} \\
16,2 \mathrm{~N} / \mathrm{mm}^{2}\end{array}$ & $\begin{array}{l}\sigma_{\mathrm{gr}, \mathrm{max}, \mathrm{el}, \mathrm{d}}=0,1< \\
\mathrm{d}_{\mathrm{g}, \mathrm{d}}=0,21 \\
\mathbf{O K}\end{array}$ \\
\hline Level III & \multicolumn{3}{|c|}{ 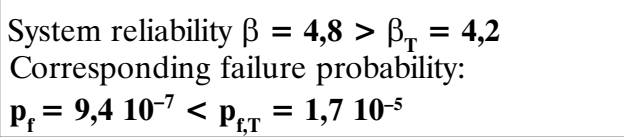 } \\
\hline
\end{tabular}

\section{Conclusions}

For the evaluation of the bearing capacity of existing structures, the interest in probabilistic evaluation methods is growing. This paper describes a methodology to calculate the reliability of structural systems. The focus is on a methodology that results in an accurate value of the system reliability index, within an acceptable CPU time. Therefore, use is made of a procedure based on Directional Sampling or Monte Carlo Sampling with Variance Increase and an adaptive Meta-Model. Using an adaptive Meta-Model, the limit state function is only evaluated if needed.

Besides low order polynomial Response Surfaces, the use of Splines and Neural Networks is incorporated. 
Based on several benchmark examples, their mutual efficiency is discussed. The advantages and drawbacks are clear from the examples presented. From these examples it is evident that Response Surfaces work well for problems that can be easily described by a low order polynomial. In case the limit state function is more complex, the use of Splines and Neural Networks demonstrated to be beneficial.

The practical application treats the safety assessment of the Romanesque city wall of Leuven (B). The focus of the application is mainly on the structural stability of the most critical part of the wall. The structural safety is assessed at different levels. Because of the uncertainties on geometry, soil resistance and loading, a structural evaluation is also performed based on probabilistic techniques. For the reliability analysis, use is made of simulation procedures combined with an adaptive meta-model. This is done, first, to check the present safety of the wall and, second, to propose a consolidation and strengthening treatment. In both cases, the probabilistic evaluation method results in an accurate value of the failure probability. In combination with a preset target value, this results in an objective way to assess the safety.

\section{Acknowledgement}

The grant offered by the Institute for the encouragement of Innovation by Science and Technology in Vlaanderen (IWT-Vlaanderen) is gratefully acknowledged.

\section{References}

1. Rosiers, M.; Van Cayseele, P. and Van Meerbeek, W. De financiering van de restauratiebehoefte. Brussels, Koning Boudewijn Stichting, 1998. 100 p.

2. Croci, G. The conservation and structural restoration of architectural heritage, Computational Mechanics Publications Southampton, 1998. 251 p.

3. Icomos, Recommendations for the analysis, conservation and structural restoration of architectural heritage, ICOMOS, International Scientific Committee for Analysis and Restoration of Structures of Architectural Heritage, 2001. Draft Version No 11.

4. Van Balen, K.; Mateus, J.; Binda, L. and Baronio, G. Expert system for the evaluation of the deterioration of ancient brick structures - scientific background for the evaluation of the deterioration of ancient brick structures, European Community, Energy, Environment and sustainable development, 1997. Research report, No 8, Vol 1.

5. Diamantidis, D. Assessment of Existing Structures, Joint Committee of Structural Safety JCSS, Rilem Publications S.A.R.L., The publishing Company of Rilem, 2001. 159 p.

6. EC1, Eurocode 1, Basis of design and Action on Structures, 1994.

7. Frangopol, D. M. and Kong, J. S. Bridge management based on reliability states and whole life costing: from theory to implementation, Structural Faults and Repair, 2001 .
8. Melchers, R. E. Structural Reliability, Analysis and Prediction, Ellis Horwood Series in Civil Engineering, 1999.

9. Schuëller, G. I. Past, Present \& Future of simulation-based Structural Analysis, International Colloquium, Euro-Sibram, 2002.

10. Waarts, P. H. Structural reliability using finite element methods, PhD thesis, TU Delft, Netherlands, 2000.

11. Bjørset, A.; Leira, B. J. and Remseth, S. Reliability analysis of local pipe buckling by finite element response surface methods. In: Melchers R. E. and Stewart M. G (ed.). Proc. Of ICASP 8, Applications of Statistics and Probability, 2000, No 1, p. 73-78.

12. Bucher, C. G.; Chen, Y. M. and Schuëller, G. I. Time variant reliability analysis utilising Response Surface approach. In: Proceedings of the 2nd IFIP WG 7.5 Conference on Reliability and Optimization of Structural Systems, 1998.

13. Bucher, C. G. and Bourgund, U. A fast and efficient response surface approach for structural reliability. Structural Safety, 1990, Vol 7, p. 57-66.

14. Bucher, C. G.; Chen, Y. M. and Schuèller, G. I. Time variant reliability analysis utilising Response Surface approach. In: Thoft-Cristensen P. (ed.), Reliability and optimization of structural system '88, Lecture notes in Engineering, Springer, 1989, p. 1-14.

15. Faravelli, L. Response Surface Approach for Reliability Analysis. Journal of Engineering Mechanics, ASCE, 1989, Vol 115(2), p. 2763-2781.

16. Myers, R. H. and Montgomery, R. C. Response Surface Methodology. New York: John Wiley \& Sons, Inc, 1995.

17. Petersen, R. G. Design and analysis of experiments. New York: Marcel Dekker, inc., 1985.

18. Martin, A. Neural network learning: theoretical foundations. Cambridge: Cambridge University Press, 1999.

19. Saad, D. On-line learning in neural networks. Cambridge University Press, 1998.

20. Simon, H. Neural networks: a comprehensive foundation. Prentice Hall Upper Saddle River, 1999.

21. Suykens, J. Data Mining and Neural Networks, lecture notes: Department of Electrical Engineering, KULeuven, 2001.

22. Schueremans, L. Probabilistic evaluation of structural unreinforced masonry. PhD, KULeuven, Belgium, 2001.

23. Schueremans, L. and Van Gemert, D. System reliability methods using advanced sampling techniques. ESREL 2003, 2003, p. 1425-1432.

24. Schueremans, L. and Van Gemert, D. Use of Neural Networks and Splines in design and assessment of civil engineering structures. In: The Seventh International Conference on the Application of Artificial Intelligence to Civil and Structural Engineering, CD-Rom 2003.

25. Maes, M. A.; Breitung, K. and Dupois, D. J. Asymptotic Importance Sampling. Structural Safety, 1993, Vol 12(3), p. 167-186.

26. Mathworks, The Matlab 6.5: Reference Manual, Natick, MA, USA, http://www.mathworks.com., 2002.

27. De Boor, C. 2001. A Practical Guide to Splines. Applied Math. Sciences, Vol 27, Springer Verlag, New York, 1978. 392 p. (revised edition). 
28. Gayton, N.; Bourinet, J. M. and Lemaire, M. CQ2RS : A new statistical approach to the response surface method for reliability analysis. Structural Safety, 2003, Vol 25, p. 99-121.

29. Lemaire, M. and Mohammed, A. Finite element and reliability; a happy marriage ? In: Nowak A. (ed), Reliability and optimization of structural systems, 2000.

30. Gomes, H. M.; Awruch, A. M. Comparison of response surface and neural network with other methods for structural reliability analysis. Structural Safety, 2004, Vol 26, p. 49-67.

31. Hagan, M. T.; Demuth, H. B. and Beale, M. H. Neural Network Design. Boston MA: PWS Publishing, 1996.

32. Moller, M. F. A scaled conjugate gradient algorithm for fast supervised learning. Neural Networks, 1993, Vol 6, p. 525-533.
33. Hagan, M. T. and Menjaj, M. Training feed-forward networks with the Marquardt algorithm. IEEE Transactions on Neural Networks, 1994, Vol 5(6), p. 989-993.

34. Schueremans, L. Use of Splines and Neural Networks in structural reliability - new issues in the applicability of probabilistic techniques for construction technology, ongoing postdoctoral research, KULeuven, url: http:// www.kuleuven.ac.be/bwk/materials/Research/index.htm, 2004.

35. Schueremans, L. and Van Gemert, D. Structural Assessment and Consolidation of the Medieval Wall of Leuven, Strumas VI, 22-25 September, Rome, Italy, 2003.

36. Schueremans, L.; Van Gemert, D.; Handbogenhof, PV30049, Internal Report, KULeuven, in Dutch, 2003. 